\title{
Magnet Temperature Estimation in Permanent Magnet Synchronous Machines Using the High Frequency Inductance
}

\author{
David Reigosa, Daniel Fernández, María Martínez, J. M. Guerrero, A. B. Diez and Fernando Briz \\ "University of Oviedo. Dept. of Elect., Computer \& System Engineering, Gijón, 33204, Spain. \\ diazdavid@uniovi.es, fernandezalodaniel@uniovi.es, martinezgmaria@uniovi.es, guerrero@uniovi.es, abdiez@uniovi.es, \\ fernando@,isa.uniovi.es
}

\begin{abstract}
Permanent magnet synchronous machines (PMSMs) torque production capability depends on the permanent magnets (PMs) magnetization state, which can be affected by PMs temperature and of the current flowing throughout the stator windings; knowledge of the PMs temperature can be therefore of great importance both for control and monitoring purposes. PMs temperature can be measured or estimated; PM temperature measurement is not easy and is not normally implemented in commercial drives. PM temperature estimation methods can be divided into thermal models based, BEMF based and signal injection based methods. Existing HF signal injection methods estimate the PM temperature from the measured stator $\mathrm{HF}$ resistance. Unfortunately the resistance is also affected by magnetoresistive effect, which can limit the accuracy of the estimates. This paper proposes the use of the stator $d$-axis HF inductance for PM temperature estimation. This makes temperature estimation insensitive to magnetoresistive effect. In addition, it allows the use of higher frequencies, reducing the adverse impact of the injected signal on machine performance. ${ }^{1}$
\end{abstract}

Keywords-Permanent magnet synchronous machines, magnet temperature estimation, high frequency signal injection.

\section{Introduction}

Design and control of permanent magnet synchronous machines (PMSMs) have been the focus of significant research efforts during the last decades due to their high dynamic response, torque density and efficiency. PMSMs performance depends on the permanent magnets (PMs) magnetization state [1]-[2], which is affected by PMs temperature [2]-[8] and of the current flowing through the stator windings [9]-[12]. An increase of the PM temperature reduces the PM remanent flux (i.e. magnetization state) and consequently the torque production capability, permanent demagnetization being also possible [2]-[13]. These

\footnotetext{
1 This work was supported in part by the Research, Technological Development and Innovation Programs of the Spanish Ministry Economy and Competitiveness, under grant MINECO-17-ENE2016-80047-R.
}

concerns have boosted the interest in the development of PM temperature measurement/estimation methods.

Direct PM temperature measurement is not easy. Since PMs are moving parts, cabling to a rotating part or wireless transmission system are required [6]-[8], [14], which is undesirable due to robustness and cost issues. An alternative to direct PM temperature measurement is temperature estimation. PM temperature estimation methods can be roughly divided into thermal models [15]-[19], BEMF based methods [8],[20]-[22] and signal injection methods [3]-[8], [23]-[24], [34]. Thermal models require precise knowledge of the machine geometry, materials and cooling system, the model being specific therefore for each machine design. BEMF based methods use the induced stator terminal voltage. Concerns for these method is that they require that the machine is rotating, knowledge of $d$ and $q$-axis inductance maps vs. stator current being also needed. High frequency (HF) signal injection based methods measure the machine response to a high frequency signal injected in the stator via inverter. Appealing properties of these methods are that they can be used in the whole speed range and do not require previous knowledge of machine parameters. In addition these methods require knowledge of the stator temperature, though this is not considered a concern as it is often measured in standard drives [3]-[8].

Existing HF signal injection based methods rely on the dependence of the stator HF resistance on the magnet HF resistance, which is a function of magnet temperature. Unfortunately the PM resistance is sensitive to magnetoresistive effect [25]-[27]. Though its compensation is possible, this increases the complexity and the parameter sensitivity of the method [5].

This paper proposes the use of the stator $d$-axis HF inductance to estimate PM temperature. The inductance is not affected by magnetoresistive effect, resulting in a simpler implementation and higher accuracy. Furthermore, using the inductance enables the use of higher frequencies. This increases the spectral separation with the fundamental excitation, making filtering easier, unwanted effects due to HF signal injection as torque ripple, noise and vibration being also reduced. It is finally noted that the proposed method provides a lumped temperature estimate. Most of existing temperature 
estimation methods [3]-[5],[7]-[8], [15]-[24], have the same restriction, i.e. do not provide any information on the spatial temperature distributions. It is noted in this regard that thermal models can be extended to 3D [15]-[19] to provide spatial temperature distribution at a price of significant increase of the model complexity. BEMF harmonic content was also shown in [6] to contain information on PMs spatial temperature distribution.

The paper is organized as follows: Principles of PM temperature estimation using the HF inductance are discussed in section II; HF inductance estimation using pulsating $\mathrm{HF}$ current injection is described section III; implementation of the method is described in section IV; experimental results are provided in section V; discussion on the HF signal selection is included in section VI; conclusions are finally presented in section VII.

\section{PM temperature estimation using the HF inductance}

This section presents the physical principles of PM temperature estimation using the HF inductance. The HF model of a PMSM in the synchronous rotor reference frame is described by (1), where $v_{s d H F}^{r}, v_{s q H F}^{r}, i_{s d H F}^{r}$ and $i_{s q H F}^{r}$ are stator $d$ and $q$-axis HF voltages and currents in the rotor synchronous reference frame respectively, $R_{d H F}, R_{q H F}, L_{d H F}$ and $L_{q H F}$ are the $d$ and $q$-axis HF resistances and inductances respectively, $\omega_{r}$ is the machine speed and $p$ is the differential operator.

$$
\begin{aligned}
{\left[\begin{array}{c}
v_{s d H F}^{r} \\
v_{s q H F}^{r}
\end{array}\right]=} & {\left[\begin{array}{cc}
R_{d H F} & 0 \\
0 & R_{q H F}
\end{array}\right]\left[\begin{array}{c}
i_{s d H F}^{r} \\
i_{s q H F}^{r}
\end{array}\right]+} \\
& p\left[\begin{array}{cc}
L_{d H F} & 0 \\
0 & L_{q H F}
\end{array}\right]\left[\begin{array}{c}
i_{s d H F}^{r} \\
i_{s q H F}^{r}
\end{array}\right]+ \\
& {\left[\begin{array}{cc}
0 & -\omega_{r} L_{q H F} \\
\omega_{r} L_{d H F} & 0
\end{array}\right]\left[\begin{array}{l}
i_{s d H F}^{r} \\
i_{s q H F}^{r}
\end{array}\right] }
\end{aligned}
$$

The $d$-axis HF inductance, $L_{d H F}$, is function of the $d$-axis saturation level, which depends on the d-axis fundamental current [6], [9]-[12], [29] and PM remanent flux [5]-[6], (2).

$$
L_{d H F(I d, B r)}=L_{d H F 0}\left(1+\alpha_{i d} I_{s d}^{r}+\alpha_{i q} I_{s q}^{r}+\alpha_{B r}\left(B_{r\left(T_{r}\right)}-B_{r\left(T_{r 0}\right)}\right)\right)
$$

where $L_{d H F 0}$ is the $d$-axis $\mathrm{HF}$ inductance due to the PM remanent flux at the room temperature $T_{r 0}$ with no $d$-axis fundamental current; $\alpha_{i d}, \alpha_{i q}$ and $\alpha_{B r}$ are the coefficients linking the $d$-axis HF inductance with the $d$-axis fundamental current, $I_{s d}^{r}$, the $q$-axis fundamental current, $I_{s q}^{r}$ (due to crosscoupling), and the PM remanent flux respectively; $B_{r\left(T_{r 0}\right)}$ is the PM remanent flux at the room temperature and $B_{r\left(T_{r}\right)}$ is the PM remanent flux at an arbitrary temperature $T_{r}$. The temperature dependence of the PM remanent flux is given by $\alpha_{T}$ (3) [2], [6], [13].

$$
B_{r\left(T_{r}\right)}=B_{r\left(T_{r 0}\right)}\left(1+\alpha_{T}\left(T_{r}-T_{r 0}\right)\right)
$$

By substituting (3) into (2), (4) is obtained.

$$
L_{d H F(I d, B r)}=L_{d H F 0}\left(\begin{array}{l}
1+\alpha_{i d} I_{s d}^{r}+\alpha_{i q} I_{s q}^{r}+ \\
+\alpha_{B r} B_{r\left(T_{r 0}\right)} \alpha_{T}\left(T_{r}-T_{r 0}\right)
\end{array}\right)
$$

It is observed from (4) that the magnet temperature, $T_{r}$, can be estimated from $L_{d H F(I d, B r)}$, previous knowledge of $L_{d H F 0}$ and decoupling of the effects due to the $d$ and $q$-axis fundamental current being required.

\section{HF inductance estimation using pulsating HF current injection}

A HF current can be injected in the $d$-axis via inverter (5), i.e. aligned with the PMs to estimate $L_{d H F(I d, B r)}$; a resonant controller is used for this purpose. The HF voltages provided by the resonant controller will be of the form (6). By taking only the $d$-axis component of the resulting HF voltage complex vector, $v_{d q s H F}^{r^{*}}$ in (6), the voltage complex vector $v_{d q s H F}^{r^{\prime}},(7)$, is defined. Both (5) and (7) can be separated into positive sequence $\left(i_{d q s H F p c}^{r^{*}}\right.$ and $\left.v_{d q s H F p c}^{r^{\prime}}\right)$ and negative sequence ( $i_{d q s H F n c}^{r^{*}}$ and $v_{d q s H F n c}^{r^{\prime}}$ ) components (8)-(9), each with a magnitude equal to half of that of the original signal.

$$
\begin{aligned}
& i_{d q s H F}^{r^{*}}=\left[\begin{array}{c}
\bar{I}_{d H F}^{r^{*}} \\
\bar{I}_{q H F}^{r^{*}}
\end{array}\right]=\left[\begin{array}{c}
I_{H F}^{*} \cos \left(\omega_{H F} t\right) \\
0
\end{array}\right] \\
& v_{d q s H F}^{r^{*}}=\left[\begin{array}{c}
\bar{V}_{d s H F}^{r^{*}} \\
\bar{V}_{q s H F}^{r^{*}}
\end{array}\right]=\left[\begin{array}{c}
\left(R_{d H F}+j \omega_{H F} L_{d H F}\right) \bar{I}_{d H F}^{r} \\
\omega_{r} L_{d H F} \bar{I}_{d H F}^{r}
\end{array}\right] \\
& v_{d q s H F}^{r^{\prime}}=\left[\begin{array}{c}
\bar{V}_{d s H F}^{r^{*}} \\
0
\end{array}\right]=\left[\begin{array}{c}
\left(R_{d H F}+j \omega_{H F} L_{d H F}\right) \bar{I}_{d H F}^{r^{*}} \\
0
\end{array}\right] \\
& =\left[\begin{array}{c}
V_{d q s H F}^{r^{\prime}} \cos \left(\omega_{H F} t+\varphi_{Z d}\right) \\
0
\end{array}\right] \\
& i_{d q s H F}^{r^{*}}=\frac{I_{H F}^{*}}{2} e^{j \omega_{H F} t}+\frac{I_{H F}^{*}}{2} e^{-j \omega_{H F} t}=i_{d q s H F p c}^{r^{*}}+i_{d q s H F n c}^{r^{*}} \\
& v_{d q s H F}^{r^{\prime}}=\frac{\left|v_{d q s H F}^{r^{\prime}}\right|}{2} e^{j\left(\omega_{H F} t-\varphi_{Z d}\right)}+\frac{\left|v_{d q s H F}^{r^{\prime}}\right|}{2} e^{j\left(-\omega_{H F} t+\varphi_{Z d}\right)} \\
& =v_{d q s H F p c}^{r^{\prime}}+v_{d q s H F n c}^{r^{\prime}}
\end{aligned}
$$

The $d$-axis HF impedance, (10), can be obtained either from the positive or negative sequence components, (8) and (9), $\varphi_{Z_{d H F}}$ (11) being the phase of the $d$-axis HF impedance (10). The $d$-axis HF inductance can be obtained from (12). 


$$
\begin{aligned}
& Z_{d H F}=R_{d H F}+j \omega_{H F} L_{d H F}=\frac{v_{d q s H F p c}^{r^{\prime}}}{i_{d q s H F p c}^{r^{*}}}=\frac{v_{d q s H F n c}^{r^{\prime}}}{i_{d q s H F n c}^{r^{*}}} \\
& \varphi_{Z_{d H F}}=\tan ^{-1}\left(\frac{\omega_{H F} L_{d H F}}{R_{d H F}}\right) \\
& L_{d H F}=\frac{Z_{d H F} \sin \left(\varphi_{Z_{d H F}}\right)}{\omega_{H F}}
\end{aligned}
$$

From (4) and (12) the magnet temperature (13) is finally obtained.

$$
\begin{aligned}
T_{r}= & \frac{L_{d H F}-L_{d H F 0}-L_{d H F 0} \alpha_{i d} I_{s d}^{r}-L_{d H F 0} \alpha_{i q} I_{s q}^{r}}{L_{d H F 0} \alpha_{B r} B_{r\left(T_{r 0}\right)} \alpha_{T}}+ \\
& +\frac{L_{d H F 0} \alpha_{B r} B_{r\left(T_{r 0}\right)} \alpha_{T} T_{r 0}}{L_{d H F 0} \alpha_{B r} B_{r\left(T_{r 0}\right)} \alpha_{T}}
\end{aligned}
$$

\section{Implementation}

Fig. 1 shows the general block diagram used for the implementation of the method, including inverter control and injection of the HF pulsating signal using resonant controller [5]. Fig. 2 shows the signal processing required for magnet temperature estimation. Inputs to the temperature estimation block are the output voltage of the HF resonant current controller $v_{d q s H F}^{r *}(6)$, the commanded HF current $i_{d q s H F}^{r *}$ (5) and the magnitude of the fundamental $d$ and $q$-axis currents, $I_{s d}^{r}$ and $I_{s q}^{r}$ respectively. Two band stop filters, $B S F 1$ and $B S F 2$, are used to remove the negative sequence components of the HF current and voltage. The $d$-axis impedance, $Z_{d H F}$, is estimated from the positive sequence component of the commanded HF current $i_{d q s H F p c}^{r *}$ and the $d$-axis component of the HF current resonant controller output voltage $v_{d q s H F}^{r^{\prime}}$ using (10); the $d$-axis inductance, $L_{d H F}$, is estimated using (12); The magnet temperature is finally estimated using (13).

As it can be observed from (10), to estimate the high frequency impedance the proposed method requires the high frequency current and voltage. While current sensors are already present for current control purposes, voltage sensors are practically never used, meaning that the commanded voltage must be used instead (output of the HF resonant controller, see Fig. 1). Errors between actual and commanded voltage will exist due to the non-ideal behavior of the inverter, mainly due to the inverter dead-time, variations of the DC bus voltage and the voltage drop in the power devices.

- Dead-time results in errors in both the magnitude and phase of the injected voltage with respect to the commanded voltage. A large variety of methods to compensate the dead-time effects have been proposed [35]-[37], the method proposed in [35] has been used for this research.
- Variations of the dc bus voltage, would produce errors in the magnitude of the injected voltage with respect to the commanded value, and consequently in the estimated high frequency impedance. However, since dc bus voltage is normally measured in industrial drives, these variations can be easily compensated.

- Voltage drops in the power devices also results in errors in the magnitude of the injected voltage with respect to the commanded value. For the power modules that have been used in this work, 7MBP100VDA120-50 [30], voltage drop in the power devices have been found to be negligible compared with the injected HF voltage, no compensation has been therefore implemented. The internal resistance of the power switches is $\approx 20 \mathrm{e}^{-3} \Omega$ at $100 \mathrm{~A}$ and $25^{\circ} \mathrm{C}$, which is more than two full orders of magnitude smaller than the overall machine highfrequency impedance $\left(Z_{d H F} \approx(4.1+j 1.9) \Omega\right.$ at $25{ }^{\circ} \mathrm{C}$ and $250 \mathrm{~Hz}$ ); therefore, it can be safely neglected.

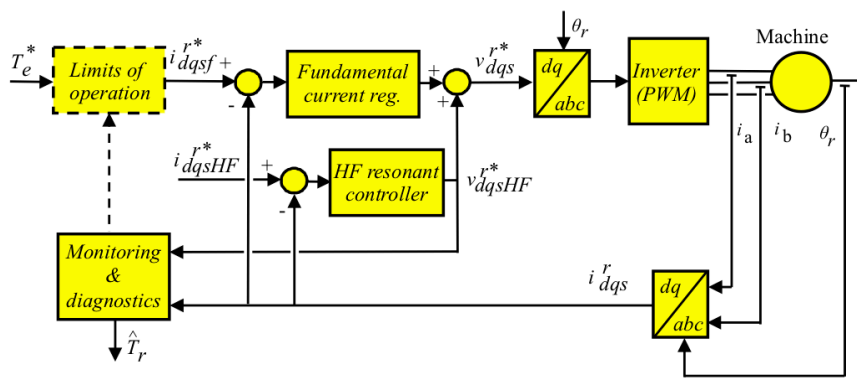

Fig. 1.- Injection of a HF pulsating current. Dashed lines indicate optional functionalities.

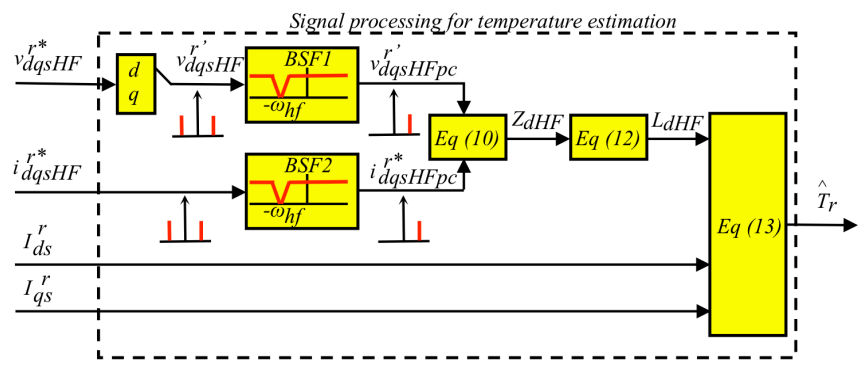

Fig. 2.- Schematic representation of the signal processing to estimate the magnet temperature using pulsating HF current injection.

\section{Experimental results}

\begin{tabular}{|l|l|}
\hline \multicolumn{2}{|c|}{ Table I. Machine parameters } \\
\hline$P_{\text {RATED }}(\mathrm{kW})$ & 7.5 \\
\hline$I_{\text {RATED }}(\mathrm{A})$ & 14 \\
\hline$\omega_{\text {RATED }}(\mathrm{rpm})$ & 1000 \\
\hline Stator slots & 36 \\
\hline Poles & 6 \\
\hline Rotor radius $(\mathrm{mm})$ & 54.2 \\
\hline Airgap length $(\mathrm{mm})$ & 0.8 \\
\hline Inner stator radius $(\mathrm{mm})$ & 55 \\
\hline Outer stator radius $(\mathrm{mm})$ & 88 \\
\hline Permanent magnets $(\mathrm{NdFeB})$ & BMN-42M [38] \\
\hline
\end{tabular}


a)
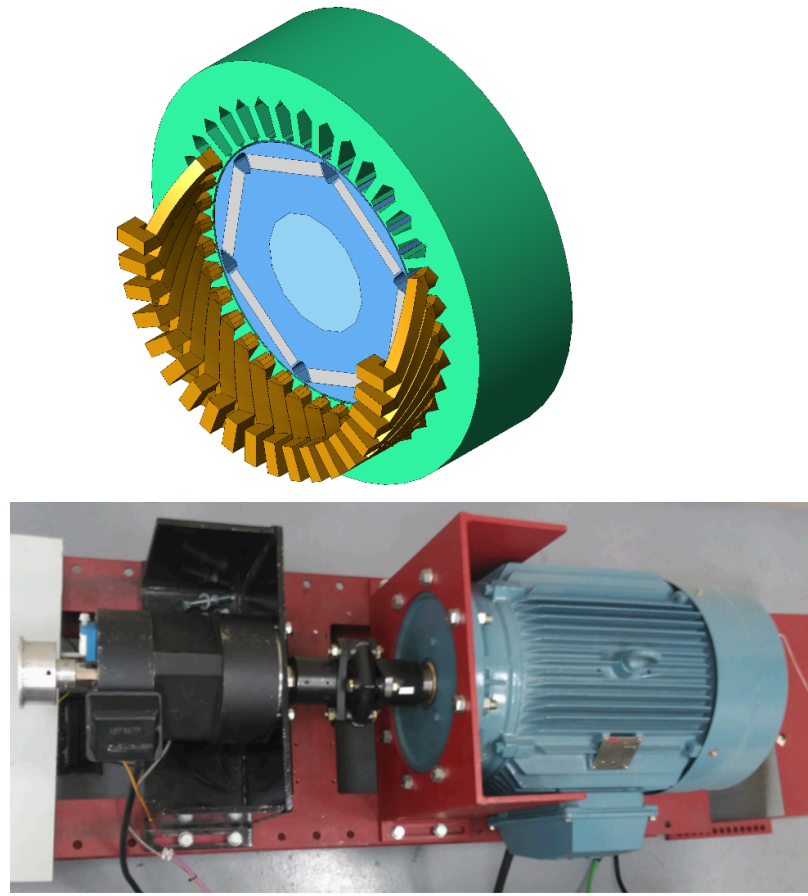

Fig. 3.-. (a) Schematic representation of the test machine and (b) picture of the test bench.

The proposed method has been tested on an IPMSM, its schematic design is shown in Fig. 3a. Main dimensions and ratings are shown in Table I. The test machine is driven by a power converter equipped with $1200 \mathrm{~V}, 100 \mathrm{~A}$ IGBT power modules (7MBP100VDA120-50 [30]). Standard Space Vector Modulation was used. The switching frequency was $10 \mathrm{kHz}$. The test bench can be seen in Fig. 3b.

Fig. 4a shows $L_{d H F}$ vs. $I_{d}$ and $I_{q}$ when the magnet temperature is constant for a frequency of the HF signal of $250 \mathrm{~Hz}$. It is observed that $L_{d H F}$ is barely affected by $I_{q}$, meaning that for this particular machine, the cross-coupling between $d$ and $q$-axis is negligible, i.e. $L_{d H F 0} \alpha_{i q} \approx 0 \mathrm{mH} / \mathrm{A}$ (13); consequently load will have reduced impact on the estimated temperature. However, $L_{d H F}$ is seen to be highly dependent on $I_{d}$, a valued of $L_{d H F 0} \alpha_{i d}=0.207 \mathrm{mH} / \mathrm{A}$ (13) has been obtained experimentally. Compensation of $I_{d}$ effects will be therefore required for accurate temperature estimation. Fig. $4 \mathrm{~b}$ shows $L_{d H F}$ vs. the frequency of the HF for different $I_{d}-I_{q}$ sets. It is observed that the $L_{d H F}$ decreases as frequency increases Finally, Fig. 4c shows $\alpha_{i d}$, which is shown to be rather insensitive to frequency and q-axis current levels.

The performance of the proposed method with an IPMSM is shown in Fig. 5-Fig. 6. Data was collected with both torque and speed being varied from zero to their rated values in steps of $0.1 \mathrm{pu}$; MTPA is not implemented, i.e. $I_{s d}^{r}=0$ for $\omega_{r}<1 \mathrm{pu}$ and $I_{s d}^{r} \neq 0$ for $\omega_{r}>1 \mathrm{pu}$. The reason for not using MTPA is to analyze the effects of changes in $I_{q}, I_{d}$ and $\omega_{r}$ separately. To assess the accuracy of the method, PMs temperatures were measured in real time using the system described in appendix A. Fig. 5a shows the measured PM temperature obtained as the average of the three temperature sensors. It is observed from Fig. 5a that the rotor temperature increases with the load due to the copper, eddy current and hysteresis losses, which was an expected result [3]-[8]. The rotor temperature also increases with the speed due to the increased eddy currents and hysteresis losses with frequency. Fig. 5b shows the estimated $d$-axis HF inductance $L_{d H F}$ using (12). Fig. 5c shows the estimated $d$-axis HF inductance after decoupling the effect of $I_{d}, L_{d H F}^{\prime}(14)$; variation observed in this figure being exclusively due to PM temperature variation.

$$
L_{d H F}^{\prime}=L_{d H F}-L_{d H F 0} \alpha_{i d} I_{s d}^{r}
$$

Fig. 6a shows the estimated PM temperature using $\alpha_{B r} B_{r\left(T_{r 0}\right)} \alpha_{T}=0.038 \mathrm{mH} /{ }^{\circ} \mathrm{C}$ (13). Fig. $6 \mathrm{~b}$ shows the PM temperature error between measured and estimated temperatures. It can be observed that speed and load have almost no impact on the temperature estimation error. Maximum error in the estimated PM temperature is $<4^{\circ} \mathrm{C}$.

a)

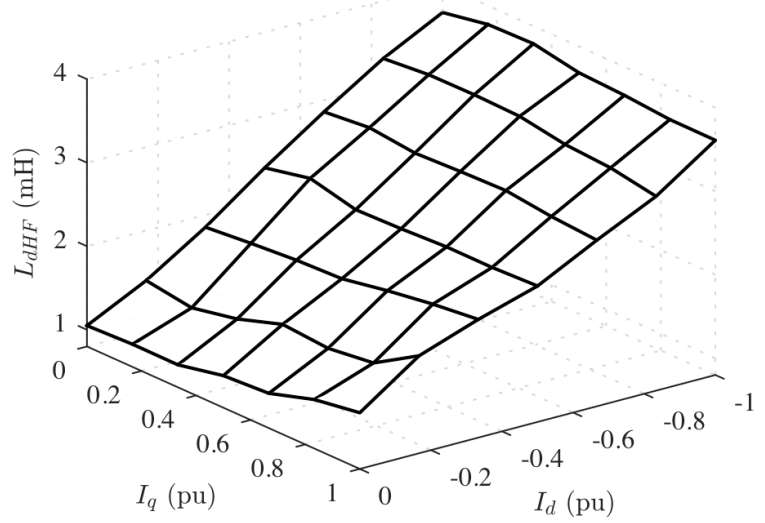

$$
\begin{array}{ll}
\bigcirc I_{d}=0 \mathrm{pu} ; I_{q}=0 \mathrm{pu} & \square I_{d}=0 \mathrm{pu} ; I_{q}=1 \mathrm{pu} \\
\diamond I_{d}=-1 \mathrm{pu} ; I_{q}=0 \mathrm{pu} & \times I_{d}=-1 \mathrm{pu} ; I_{q}=1 \mathrm{pu}
\end{array}
$$

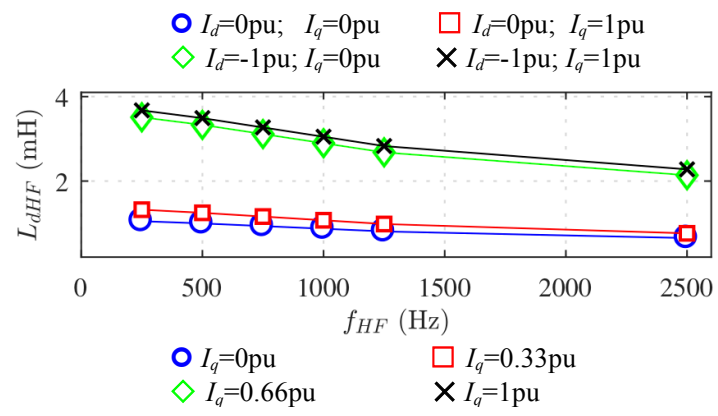

b)

c)

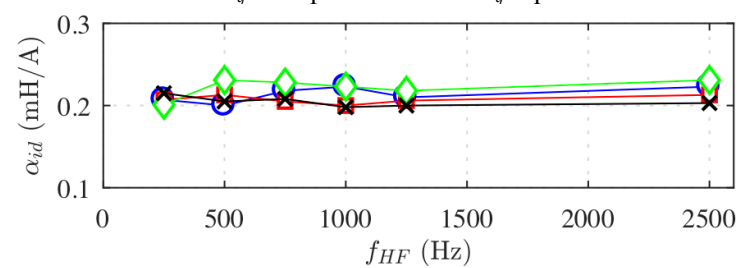

Fig. 4.-. a) $L_{d H F}$ variation with $i_{d}$ and $i_{q}$ for the case of a constant magnet temperature and frequency of the HF signal $\left(f_{H F}\right)$ of $250 \mathrm{~Hz}$. b) $L_{d H F}$ variation with $f_{H F}$ for the case of a constant magnet temperature and for different values of $I_{d}$-and $I_{q}$ combinations. c) $\alpha_{i d}$ variation with $f_{H F}$ for the case of a constant magnet temperature and various $I_{q}$ values. 

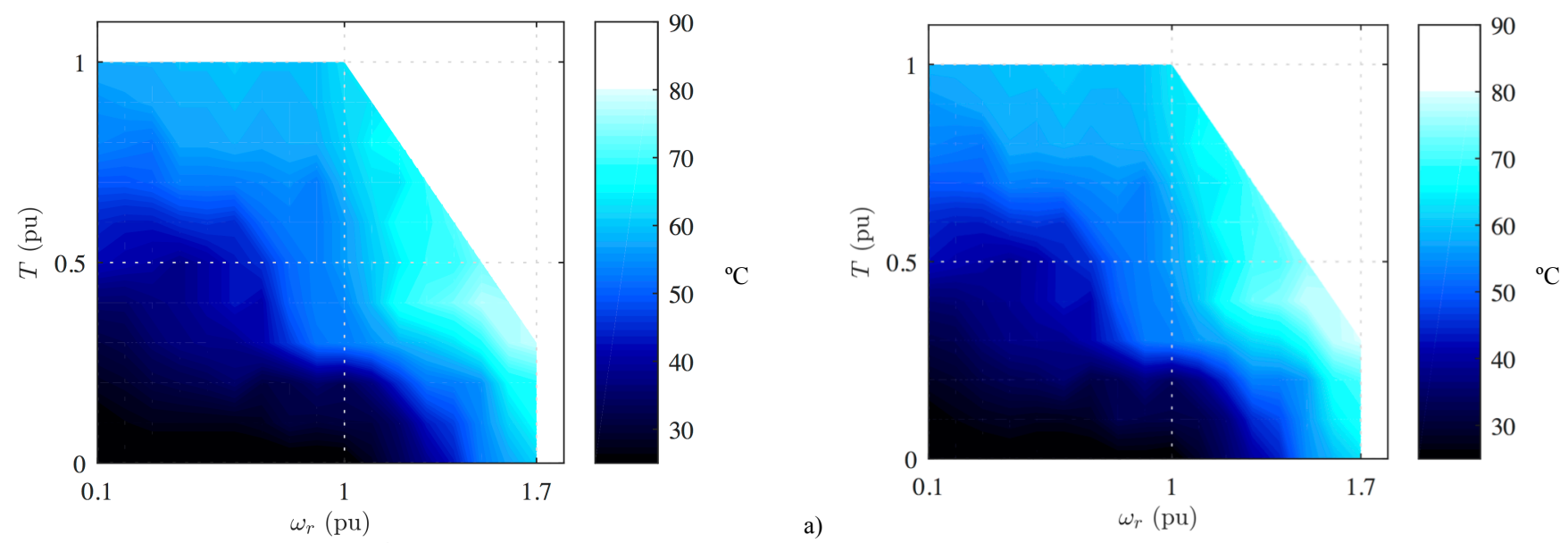

b)
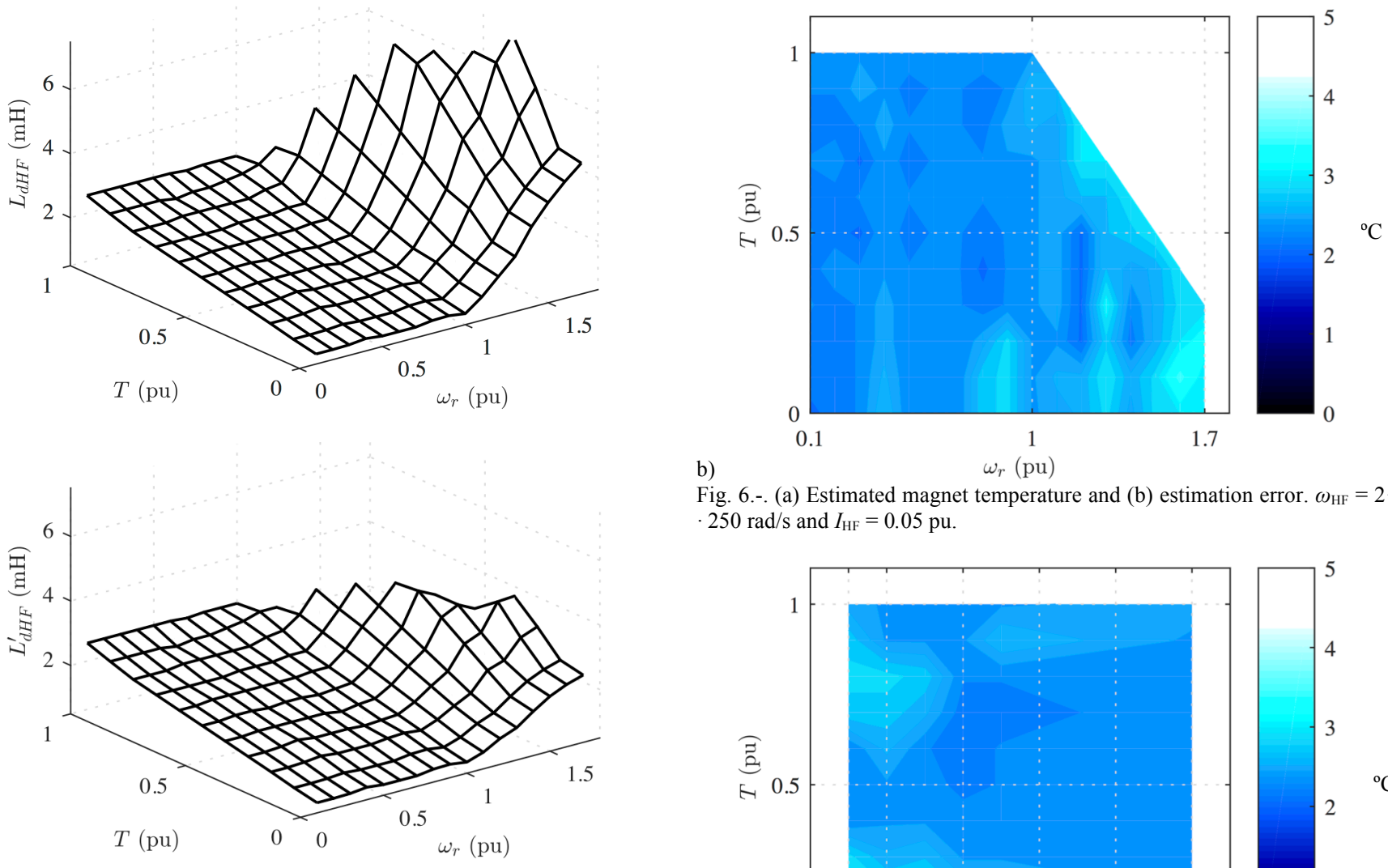

b)

Fig. 6.-. (a) Estimated magnet temperature and (b) estimation error. $\omega_{\mathrm{HF}}=2 \cdot \pi$ $250 \mathrm{rad} / \mathrm{s}$ and $I_{\mathrm{HF}}=0.05 \mathrm{pu}$

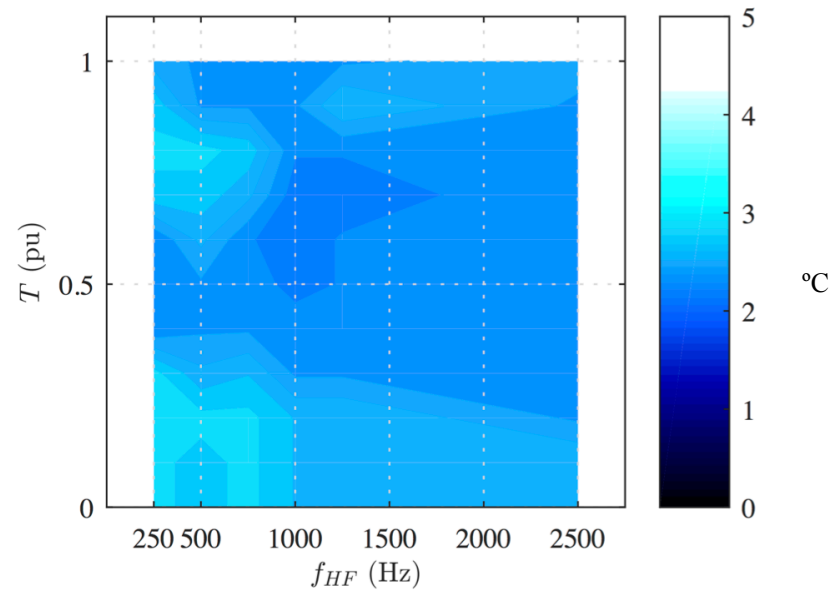

\section{HF signal selection}

Selection of the frequency $\left(f_{H F}\right)$ and magnitude $\left(I_{H F}\right)$ of the injected HF current involves a trade-off between the accuracy of method and the potential adverse effects on the operation of the drive.

Fig. 7.-. Estimation error. $\omega_{\mathrm{r}}=1 \mathrm{pu}$ and $I_{\mathrm{HF}}=0.05 \mathrm{pu}$.

\section{a) Frequency selection}

The proposed method uses the stator $d$-axis HF inductance to estimate PM temperature. Higher frequencies will increase therefore the weight of the inductive component (desired component) over the resistive component (undesired component) in the overall high frequency impedance, improving the accuracy. Fig. 7 shows the PM temperature 
error at a fixed speed, $1 \mathrm{pu}$ when the frequency of the HF signal changes from 250 to $2500 \mathrm{~Hz}$. It is observed that the estimation error slightly decreases as the frequency of the HF signal increases, higher frequencies would be therefore preferred. In addition, higher frequencies will increase the spectral separation with the fundamental excitation, making filtering easier, and reducing unwanted effects due to $\mathrm{HF}$ signal injection as torque ripple, noise and vibration. It is noted however that increasing the frequency could increase the induced machine losses and consequently temperature, which results in a reduction of the magnet strength and could even cause permanent demagnetization. PMSM's losses can be divided into copper losses, iron losses and PM losses. Copper losses due to the HF signal injection can be expressed by (15) [4], where $R_{H F}$ is the HF resistance of the stator winding, and $I_{H F}$ is the magnitude of the injected HF current. Assuming that $R_{H F}$ does not change with the frequency of the HF signal, it can be concluded from (15) that the copper losses do not depend on the frequency of the HF signal. This assumption is valid whenever the skin depth (16) is bigger than the radius of the stator wiring, where $\rho$ and $\mu$ are the resistivity and magnetic permeability of the material [26]-[27].

$$
\begin{aligned}
& P_{\mathrm{Cu}_{-} H F}=R_{H F} I_{H F}^{2} \\
& \delta=\sqrt{\frac{2 * \rho}{2 * \pi * f_{H F} * \mu}} \\
& P_{\text {iron }}=P_{\text {hyst }}+P_{\text {eddy }} \\
& P_{\text {hyst }}=K_{h} f_{H F} B\left(1+\frac{k}{B} \Delta B_{H F}\right) \\
& P_{\text {eddy }}=K_{e} f_{H F}^{2}\left|B_{H F}\right|^{2} \\
& P_{\text {eddy_mag }}=K_{e_{-} m a g} \frac{\left(B_{H F} f_{H F}\right)^{2}}{\rho}
\end{aligned}
$$

Both the stator and rotor iron losses can be further divided into hysteresis and the eddy current losses (17), which can be approximated using (18) and (19), where $f_{H F}$ is the frequency of the HF signal, $B$ is the flux density peak value, $B_{H F}$ is the HF flux density peak value, $\Delta B_{H F}$ is the flux reversal associated with a minor loop and $k, k_{e}$ and $k_{h}$ are constants that depend on material thickness, form and density [4], [31].

Finally, the magnet eddy current losses can be expressed as (20), where $\rho$ is the resistivity of the magnet and $k_{e \text { mag }}$ is a constant that depends on permanent magnet thickness, form and density [4], [32], [33].

It is observed from (20) that the magnet eddy current losses increase with the frequency of the HF signal. This is valid under the assumption that the skin effect can be neglected.

For the test machine (see Fig. 3a), the magnets' depth, i.e. distance between the rotor surface and the PMs, equals the skin effect depth for a frequency of $\approx 975 \mathrm{~Hz}$; meaning that the

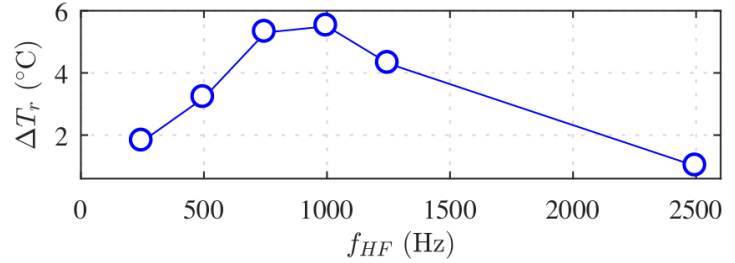

Fig. 8.-. Steady state magnet temperature increase, $\Delta T_{r}$, due to the HF current injection. $I_{\mathrm{HF}}=0.05 \mathrm{pu}, \omega_{\mathrm{r}}=1 \mathrm{pu}$ and $I_{d}=I_{q}=0 \mathrm{pu}$.

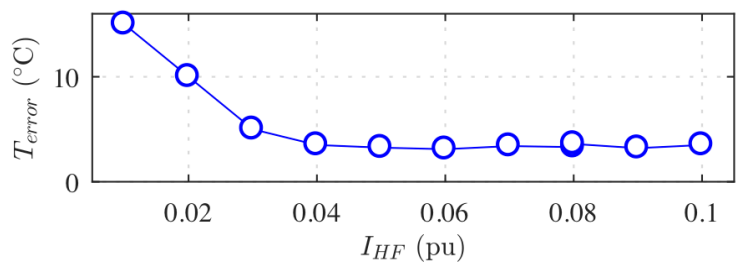

Fig. 9.-. Temperature estimation error vs. $I_{\mathrm{HF}} . \omega_{\mathrm{r}}=1 \mathrm{pu}, I_{d}=I_{q}=0 \mathrm{pu}$ and $T_{r}=25^{\circ} \mathrm{C}$.

PMs' losses, and consequently their temperature, will increase with frequency for frequencies $f_{H F}<975 \mathrm{~Hz}$, and will decrease for frequencies $f_{H F}>975 \mathrm{~Hz}$. Fig. 8 shows the steady state PM temperature increase due to the HF current injection; the PMs' temperature was measured after 60 minutes of continuous HF current injection, it was verified that the machine was in thermal steady state. As expected, the maximum temperature increase occurs for $f_{H F} \approx 975 \mathrm{~Hz}$. It can be concluded from this discussion that, for the test machine used in this paper (see Fig. 3a), frequencies of the HF signal close to $975 \mathrm{~Hz}$ should be avoided. In addition the frequency of the HF signal $f_{H F}$ plus the machine excitation frequency $\left(f_{r}\right)$ needs to be smaller than half of the switching frequency (Nyquist frequency) [5][7], which is $10 \mathrm{kHz}$ for the experimental setup used in this paper. Taking also into account that the estimation error slightly decreases as the frequency of the HF signal increases, see Fig. 7, $>975 \mathrm{~Hz}$ would be preferred.

b) Magnitude selection

It is obvious from (15), (17)-(20) that decreasing the magnitude of the injected HF current, $I_{H F}$, reduces the machine losses, therefore decreasing $I_{H F}$ results in a reduction of the unwanted thermal effects due to the HF signal injection; also resulting in a decrease of the torque ripple, noise and vibration. Fig. 9 shows the temperature estimation error vs. $I_{H F}$. It is observed that increasing $I_{H F}$ from 0.01 to $0.05 \mathrm{pu}$ significantly increases the accuracy. However, no improvement is observed for values of $I_{H F}$ above $0.05 \mathrm{pu}$. In addition, increasing $I_{H F}$ results in an increased HF voltage, $V_{H F}$, reducing therefore the available DC bus voltage for e.g. fundamental current injection. The available DC bus voltage reduction due to the HF signal injection is rather limited for the test machine used in this work; $V_{H F} \approx 0.04 \mathrm{pu}$ when $f_{H F}$ $=2500 \mathrm{~Hz}$ and $I_{H F}=0.05 \mathrm{pu}$, this issue not being therefore a concern for this machine. $I_{H F}=0.05 \mathrm{pu}$ has been found be a good trade-off between accuracy and available DC bus voltage reduction. 

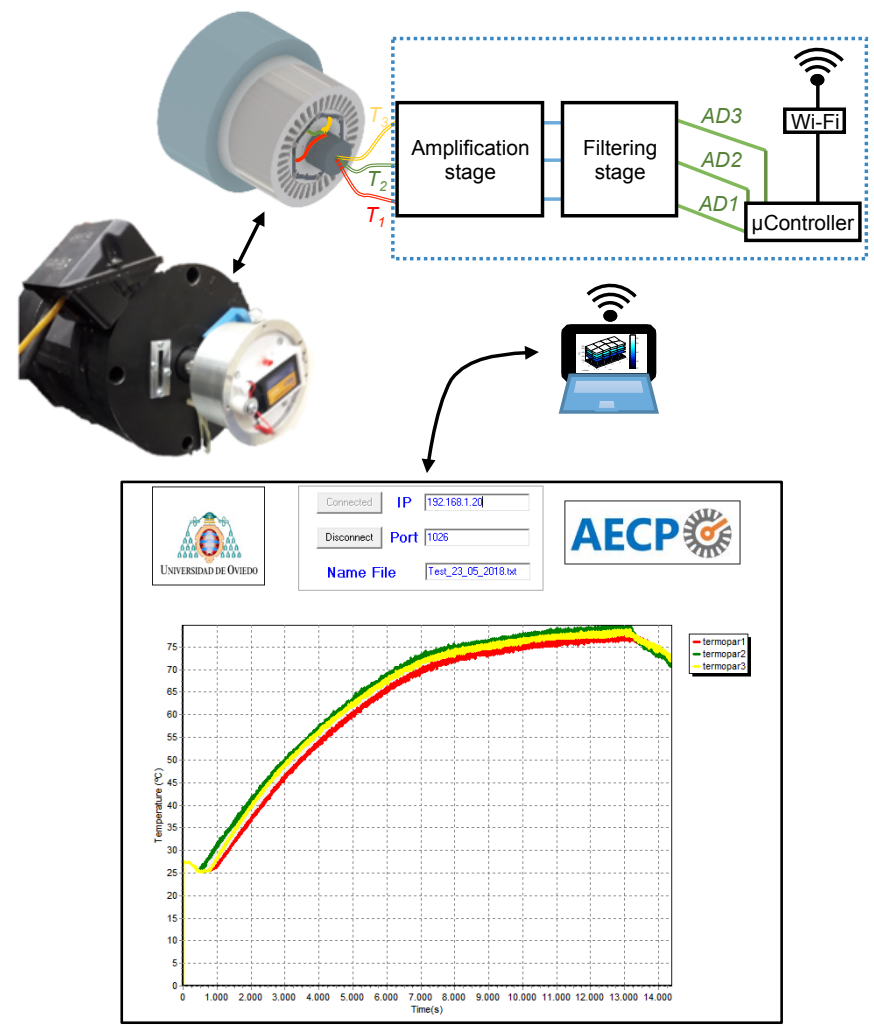

Fig. 10.- (a) Schematic representation of the temperature measurement system and (b) desktop application.

\section{Conclusions}

This paper proposes PM temperature estimation by means of HF signal injection based on the $d$-axis HF inductance. The proposed method overcomes two major limitations of HF signal injection based PM temperature estimation methods using the stator reflected magnet HF resistance: influence of magnetoresistive effect and constraints for the selection of the frequency of the injected signal. It was shown that $I_{d}$ current has an important impact over the $d$-axis HF inductance, which needs to be decoupled for accurate temperature estimation. On the contrary $I_{q}$ current has a limited impact over the $d$-axis HF inductance. Extensive experimental results have been provided to demonstrate the viability of the proposed method.

\section{Appendix A: Temperature measurement system}

\begin{tabular}{|l|l|}
\hline \multicolumn{2}{|c|}{ TABLE II. MAIN CHARACTERISTICS OF THE MEASUREMENT SYSTEM } \\
\hline Sensor Temperature limit & $250^{\circ} \mathrm{C}$ \\
\hline Resolution & $0.0936^{\circ} \mathrm{C}$ \\
\hline Measurement range & $0{ }^{\circ} \mathrm{C}$ to $125^{\circ} \mathrm{C}$ \\
\hline Bandwidth & $1.25 \mathrm{kHz}$ \\
\hline Number of sensors & 3 \\
\hline
\end{tabular}

To evaluate the performance of the proposed method, a wireless, on-line, PM temperature measurement system has been designed and built. Main blocks of the system are shown in Fig. 10; it includes temperature sensors (thermocouples), signal conditioning, $\mu$ Controller, battery and WiFi module. Ktype thermocouple temperature sensors are attached to the rotor using a thermally conductive epoxy adhesive. Thermocouple wires are taken out throughout a hollow-shaft and connected to a signal conditioning stage (amplification and filtering stages in Fig. 10), using high precision instrumentation amplifiers; the system also includes a digital temperature sensor to provide temperature at thermocouples connection point. The thermocouple signals are filtered using analog second order stages and later connected to 10-bit analog-to-digital converters (ADC) of a micro-controller ( $\mu$ Controller in Fig. 10); then the digitalized thermocouple measurements are transmitted to a central computer using a WiFi link. The maximum sampling rate of the system is $1,25 \mathrm{kHz}$, a sampling rate of $1 \mathrm{~Hz}$ was used in for the experiments shown in this paper. To supply conditioning stage, $\mu$ Controller and wireless transmission device, a power stage composed of a Li-Po battery and various DC-DC converters, is included. Fig. 10b shows a screenshot of the desktop application that has been developed.

\section{References}

[1] D. W. Novotny and T. A. Lipo, "Vector Control and Dynamics of AC Drives," Oxford Science Publications, 1996.

[2] J. F. Gieras and M. Wing, "Permanent magnet motor technology: design and application". Second edition 2002.

[3] D. Reigosa, F. Briz, M. W. Degner, P. García and J. M. Guerrero, "Magnet temperature estimation in surface PM machines during six-Step operation”. IEEE Trans. on Ind. Appl., 48(6): 2353-2361, Nov.-Dec. 2012.

[4] D. Reigosa, F. Briz, M. W. Degner, P. García and J. M. Guerrero, "Temperature issues in saliency-tracking-based sensorless methods for PM synchronous machines". IEEE Trans. on Ind. Appl., 47(3): 13521360, May-June 2011.

[5] D. Reigosa, D. Fernandez, H. Yoshida, T. Kato and F. Briz "PermanentMagnet Temperature Estimation in PMSMs Using Pulsating HighFrequency Current Injection," IEEE Trans. on Ind. Appl., 51(4): 31593168, July-Aug 2015.

[6] D. Reigosa, D. Fernandez, T. Tanimoto, T. Kato, F. Briz, "Permanent Magnet Temperature Distribution Estimation in Permanent Magnet Synchronous Machines Using Back Electromotive Force Harmonics", IEEE Trans. on Ind. Appl., 52(4): 3093-3103 July/Aug. 2016.

[7] D. Reigosa, D. Fernandez, T. Tanimoto, T. Kato, F. Briz, "Sensitivity Analysis of High-Frequency Signal Injection-Based Temperature Estimation Methods to Machine Assembling Tolerances", IEEE Transactions on Industry Applications, 52(6): 4798-4805 Nov./Dec. 2016.

[8] D. Reigosa, D. Fernandez, T. Tanimoto, T. Kato, F. Briz, "Comparative Analysis of BEMF and Pulsating High Frequency Current Injection Methods for PM Temperature Estimation in PMSMs", IEEE Trans. on Power Elect., 32(5): 3691-3699, May 2017.

[9] N. Limsuwan, T. Kato, K. Akatsu, and R. D. Lorenz, "Design and evaluation of a variable-flux flux-intensifying interior permanent- 
magnet machine," IEEE Trans. Ind. Appl., 50(2): 1015-1024, Mar./Apr. 2014.

[10] Fukushige, N. Limsuwan, T. Kato, K. Akatsu, and R. D. Lorenz, "Efficiency contours and loss minimization over a driving cycle of a variable flux-intensifying machine,"IEEE Trans. Ind. Appl., 51(4): 2984-2989, Jul./Aug. 2015

[11] B. S. Gagas, K. Sasaki, T. Fukushige, A. Athavale, T. Kato, and R. D.Lorenz, "Analysis of magnetizing trajectories for variable flux PM synchronous machines considering voltage, high-speed capability, torque ripple, and time duration," IEEE Trans. Ind. Appl., 52(5): 40294038, Sep./Oct. 2016.

[12] Athavale, K. Sasaki, B. S. Gagas, T. Kato, and R. D. Lorenz, "Variable Flux Permanent Magnet Synchronous Machine (VF-PMSM) Design Methodologies to Meet Electric Vehicle Traction Requirements with Reduced Losses," IEEE Trans. Ind. Appl., 53(5): 4318-4326, Sep./Oct. 2016.

[13] www.arnoldmagnetics.com

[14] D. Fernandez, D. Reigosa, T. Tanimoto, T. Kato and F. Briz, "Wireless Permanent Magnet Temperature \& Field Distribution Measurement System for IPMSMs”, IEEE ECCE, pp. 3996- 4003, Sept. 2015.

[15] A. M. El-Refai, N. C. Harris, T. M. Jahns, K. M. Rahman, "Thermal Analysis of Multibarrier Interior PM Synchronous Machine Using Lumped Parameter Model". IEEE Trans. on Energy Conv., 14(2): 303309, June 2004.

[16] C. Kral, A. Haumer and S. B. Lee, "A Practical Thermal Model for the Estimation of Permanent Magnet and Stator Winding Temperatures". IEEE Trans. on Pow. Elect., 29(1): 455-464, Jan. 2014.

[17] Z. J. Liu, K. J. Binns, T. S. Low, "Analysis of Eddy current and thermal problems in permanent magnet machines with radial-field topologies". IEEE Trans. on Mag., 31(3): 1912-1915, May. 1995.

[18] A. J. Grobler, S. R. Holm and G. van Schoor, "Thermal modelling of a high speed permanent magnet synchronous machine”. IEEE-IEMD, pp.319-324, May. 2013.

[19] T. Huber, W. Peters and J. Böcker, "A Low-Order Thermal Model for Monitoring Critical Temperatures in Permanent Magnet Synchronous Motors ". IET-PEMD, pp. 1-6, April 2014.

[20] A. Specht, O. Wallscheid, J. Bocker," Determination of rotor temperature for an interior permanent magnet synchronous machine using a precise flux observer," IEEE IPEC, pp. 1501-1507, May 2014.

[21] A. Specht and L. Backer,"Observer for the Rotor Temperature of IPMSM," in International Power Electronics and Motion Control Conference (EPEIPEMC), 2010.

[22] O. Wallscheid, T. Huber, W. Peters, J. Böcker," Real-Time Capable Methods to Determine the Magnet Temperature of Permanent Magnet Synchronous Motors - A Review ," IEEE-IECON'14, pp. 811-818, Nov. 2014.

[23] M. Ganchev, C. Kral and T. Wolbank, "Compensation of speed dependency in sensorless rotor temperature estimation for permanentmagnet synchronous motors," IEEE Trans. on Ind. Appl., 49(6): 24872495, Nov.-Dec. 2013.

[24] M. Ganchev, C. Kral, H. Oberguggenberger and T. Wolbank, "Sensorless rotor temperature estimation of permanent magnet synchronous motor," IEEE IECON, pp. 2018-2023, Nov. 2011.

[25] D. Reigosa, D. Fernandez, Z.Q. Zhu and F. Briz, "PMSM Magnetization State Estimation Based on Stator-reflected PM Resistance Using High Frequency Signal Injection", IEEE Trans. on Ind. Appl., 51(5): 38003810, Sept./Oct. 2015.

[26] D. Fernandez, D. Reigosa, J. M. Guerrero, Z. Q. Zhu and F. Briz, "Influence of PM Coating on PM Magnetization State Estimation Methods Based on Magnetoresistive Effect", IEEE ECCE, pp. 1-7 Sept. 2016.

[27] D. Fernandez, D. Reigosa, J. M. Guerrero, Z. Q. Zhu and F. Briz, "Permanent-Magnet Magnetization State Estimation Using High-
Frequency Signal Injection", IEEE Transactions on Industry Applications, 52(4): 2930-2940 July/Aug.2016.

[28] D. Fernandez, D. Reigosa, T. Tanimoto, T. Kato, and F. Briz, "Wireless permanent magnet temperature \& field distribution measurement system for IPMSMs,” IEEE ECCE, pp. 3996-4003, Sep. 2015.

[29] N. Bianchi and T. M. Jahns "Design, analysis, and control of interior PM synchronous machines," Tutorial Course Notes, IEEE-IAS'04, Oct. 2004.

[30] https://www.fujielectric.com/products/semiconductor/model/igbt

[31] Seok-Hee Han, T.M. Jahns and Z.Q. Zhu, "Analysis of rotor core EddyCurrent losses in interior permanent magnet synchronous machines". IEEE IAS Ann. Meeting, CD-ROM, Oct. 2008.

[32] H. Toda, Z. Xia, K. Atallah and D. Howe, "Rotor eddy-current loss in permanent magnet brushless machines". IEEE Trans. on Mag., 40(4):2104-2106, Jul. 2004.

[33] K. Atallah, D. Howe and D. Stone, "Rotor loss in permanent-magnet brushless AC machines". IEEE Trans. on Ind. Appl., 36(6):1612-1618, Nov.-Dec. 2000.

[34] D. Reigosa, D. Fernandez, M. Martinez, J. M. Guerrero, A. B. Diez and F. Briz, "Magnet Temperature Estimation in Permanent Magnet Synchronous Machines Using the High Frequency Inductance". IEEE ECCE'18, pp. 5029-5034, Sept. 2018.

[35] J.M. Guerrero, M. Leetmaa, F. Briz and R.D. Lorenz, "Inverter Nonlinearity Effects in High-Frequency Signal-Injection-Based Sensorless Control Methods", IEEE Trans. on Ind. Appl., 41:618 - 626, Mar.-Apr. 2005.

[36] J. Choi and S.-K Sul, "A new strategy reducing voltage/current distortion in PWM VSI systems operating with low ouput voltages". IEEE Trans. on Ind. Appl., 31(5):1001-1008, Sept.-Oct. 1995.

[37] D. Reigosa, F. Briz, P. García, J. M. Guerrero and M. W. Degner, "Magnet temperature estimation in surface PM machines using high frequency signal injection". IEEE Trans. on Ind. Appl., 46(4): 14681475, July-Aug. 2010.

[38] Bomatec, "NdFeB Magnets", Dec. 10 2018. [Online]. Available: https://www.bomatec.com 